\title{
A Contribution to Urban Transport System Analyses and Planning in Developing Countries
}

\author{
Giovani Manso Ávila \\ Federal University of Rio de Janeiro (UFRJ) \\ giovani@ufrj.br \\ Brazil
}

\section{Introduction}

The purpose of this chapter is to provide a contemporary statement of existing approaches to transport-land use planning in urban and regional areas to advise practising transport planners and students. The chapter concentrates on the knowledge that are available for the synthesis, analysis, and evaluation of alternative land use-transport-systems plans and regulations. First, the transportation planner must develop an understanding of the planning process before attempting to address herself to the broader polices issues. The first objective of this chapter is to provide transportation planners with an understanding of the land-use models and their application to urban and regional planning problems. The final objective covers policy, regulations and plans.

Absence of physical space between people and firms is the definition of Economists to cities. Cities appear to supply the necessity to eliminate transport costs. Density lowers the costs of interacting with other people and speeds the flow of goods, people and ideas. The location and structure of cities is driven by the desire to eliminate transport costs. In this context, transportation technologies have been the primary determinant of the location and structure of cities. There is increasing concern across the world about increasing traffic congestion and the costs it imposes, particularly on accessibility, the environment, other social factors, such as accidents, and the economy in general. Growing personal car-mileage is engendering the well-known effects on the environment and transport systems, especially roads, which are not able to cope with the increasing amounts of traffic. Further development of innovative, integrated and well-balanced policies is strongly needed. Strong and ongoing growth in mobility, especially in road traffic, means that transport trends are unsustainable if only current policies are pursued: with constraints on resources, space, safety and the environment there are only limited possibilities to extend transport supply to safeguard accessibility. It is quite clear that the need for travel cannot really be avoided; it is crucial for the performance of social and economic functions in any society. People are not travelling much more often than twenty years ago, but they are travelling further and with greater use of the private car. Increasing car ownership is a central component of this (Transland, 2000). There is a lack of knowledge about the interaction between land use and transport and the related planning consequences. Institutional demands for integrated policymaking is 
another problem. In this context, we approach in the following sections a systematic view of a transportation system planning and analysis, and its relations with land use polices, indicating the natural evolution of the cities, it's intrinsic relations with transports and the needs to intervention and control by regulations polices.

\section{Phases of Urban Development}

The phases of urban development has a link with the economic development of transportation. They are: (a) Initial capitalism phase; (b) Industrial development; and (c) Big traffic problem on the cities.

There is an hypothesis that the city is a spatial expression of certain economic structure and productions relations as follows: (a) Feudalism - It had only one administrative centre of the autarchic production that also acted as producing centre of small services. Space reduced with commutes in the majority by foot; (b) Mercantilism - The city starts to be a centre of commercial interchange and a centre administrator of commercial interchanges. One becomes producing centre of manufactures and services. The centre expands and foot did the commutes (distances about $5 \mathrm{~km}$.); and (c) Industrial Capitalism - The city becomes centre of industrial production. It has an intensification of the social division of the work producing concentration of workmanship hand and demographic growth. The city is centre of the public, private administration, of finances and advertising.

There are Advantages of agglomerations with direct communication with other producers and central offices agencies of public and private sectors: suppliers, administrative facilities, banks, competition partnership, infrastructure of services like telecommunications, light, force, post offices. Accessibility to market and workers: attraction for the diversity of services, transportation facilities. We can nominate the spatial effects of industrial capitalism as follows: (a) Big Urban Expansion; (b) Land use and occupation with variables urban functions; and (c) Development of bulk transportation to supply, manufactures, etc.

Cities in the new world have traditionally been transportation hubs. When colonisation began, the function of cities tended to be facilitating the flow of the wealth of the new world to the markets of the old world. As such, cities located either close to the sources of wealth or in natural transport hubs. Thus, Lima located near the mineral wealth of Peru. Salvador da Bahia, Rio de Janeiro and Buenos Aires were all ports. The major cities of the U.S. - New York, Boston, San Francisco and New Orleans - were all located in places where rivers meet the sea to take maximum advantage of water born transit. Even more generally, the world was dotted with smaller cities that serviced an agricultural hinterland. Because transportation costs were high, it made sense to have commercial and manufacturing centres that were physically close to the vast majority of people who worked the land. Medium sized cities dotted the landscape because they needed to be close to the farmers.

Gradually, rail networks created a reduction in transport costs and made the locations of cities more flexible. Late 19th century cities like Chicago and São Paulo grew as railroad hubs. Rail also made it possible to have fewer, bigger cities that were further from the farmland. The mechanisation of agriculture also meant that fewer people were required to work the farms, so there was less need to medium sized cities that were close to farmland.

The 20th century has seen this process continues. Trucks and improvements in rail have further reduced transport costs. The advantage of water-born transport, particularly for intra-national transport, has further disappeared. The result of this transformation can be 
seen throughout the world. In the 19th century, urban areas did well if they had advantages that favoured producers. In the 21st century, urban areas will do well if they attract potential consumers. This shift has already created a massive dislocation within the USA as the colder cities of the rustbelt have been replaced by the newer edge cities of the sunbelt.

As such, national transportation infrastructure will tend to be extremely important for the changing urban landscape. Continuing improvements in transportation will certainly continue to change the growth of cities. However, as important as this process is, it does not necessitate a new, government approach to transportation policy. As long as the government continues to develop highways that are hopefully paid for by their users this process of urban change will continue, probably in a reasonably efficient manner.

\subsection{Phase 1 - Initial Phase of Capitalism}

Phase characterised by little industrial development, little unity of production and low demographic density. Spatially we have: (a) Production centralised in a old historic centre inner circle; (b) Disposition workmanship near productions centres; (c) Industrial location as a function of territorial supply of production factors like transportation facilities; and (d) Public and private administration and financial centre in the city centre (Fig. 1).

\subsection{Phase 2 - Big Industrial Development}

From the third part of century XIX, in the European cities a bigger development of the industrial production with new characteristics was observed: (a) Bigger social division of the work; (b) Concentration of the production; (c) Bigger units manufacturer; (d) Bigger concentration of workmanship and demand for mass transport; (e) Economies of scale and agglomeration; (f) Bigger volume of production and transport; (g) Expansion of the tertiary sector (wholesale trading, banks, private and public administration), necessitating of contacts right-handers and consequent agglomeration in the centre of the city; (h) Social stratification and space segregation; and (i) Development of mass transportation networks (trams with animal traction, urban railroad network, electric tram)(Fig. 2).

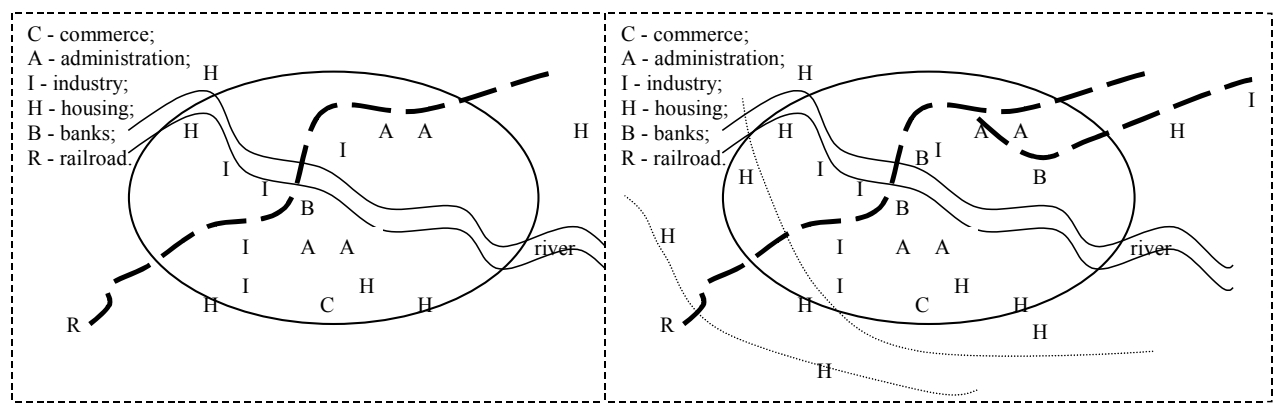

Fig. 1 and 2. Initial phase of capitalism, and big industrial development

\subsection{Phase 3 - Surface Transport Development}

With the growth of automobile industry, mainly after the end of 1st. World War, a new age of urban occupation appears, conditioned by the development of roadway modality, with growth of automobile consumption and, after a 2nd. World War, a growth in the buses consumption. As a consequence we have: (a) Occupation of the spaces between the transport axles; (b) Growth of the urban periphery; (c) Expansion of the road net and the 
demand for parking; (d) Ideal of the "motorised city" and the "proper car"; and (e) Intensification of the functional separation of land use implying in: bigger concentration of the tertiary sector in the centre, expansion of the economic functions of the tertiary, increment of the economic concentration, requirement of qualified workmanship, and demand for radial flows of transport (Fig. 3).

\subsection{Phase 4 - Big Traffic Problems on the Cities}

After a phase of full development of the individual transport, from middle of years 50 , the cities of the first world had evidenced that: "The individual transport acted as narcotic of the functioning of the urban economic system". As a consequence we can see: (a) Growing problems of congestion and security; (b) Reduction of accessibility to the city centre; (c) Lost times in transit; (d) Demand access restriction to markets and for workers mainly to central areas; (e) Changes in land use with growing demand for urban network what cause a concurrency with tertiary sector; and (f) Hanging of central areas (Fig. 4).

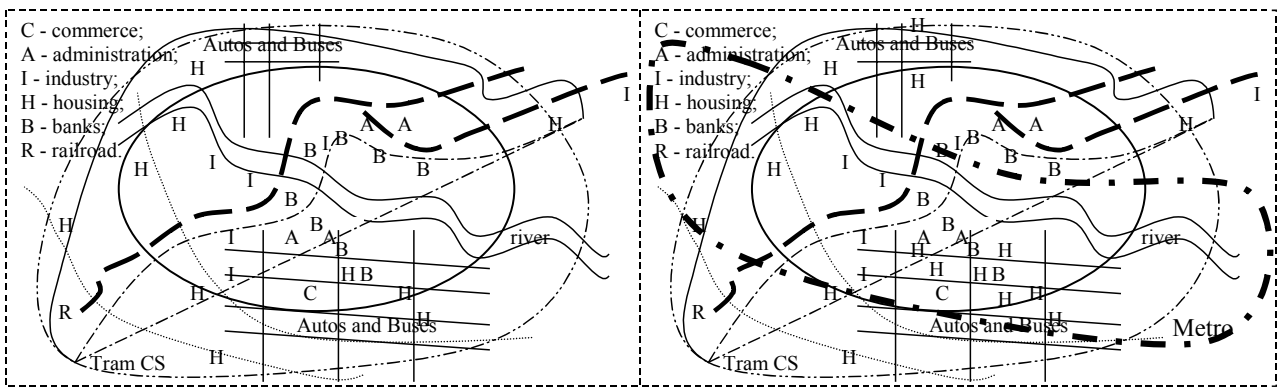

Fig. 3 and 4 . Surface transport development, and big traffic problems on the cities

From this conclusions the trends was consider mass transportation as a necessity to achieve development of urban economic system. This kind of transport allows: (a) Growth of accessibility to consumption centres; (b) Growth of accessibility to workersmanships; (c) Facility to flow of goods; (d) Turn bigger the influence area of city centres; and (e) Add new regions to urban system - conurbation.

The mass transportation systems like subways (Metro) and urban surface train - tram, have a new mission and several big cities retrieve big constructions of this kind of systems.

\section{Urban Centralisation and Transports}

Analysing the dynamics that defines a differentiated occupation of the tertiary sector of the economy in the urban context and its consequences for the transports we can see the importance of this relations.

\subsection{The Tertiary Sector of the Economy}

Characterised by the service sector, provides services to general population, including: (a) Public administration and services; (b) Private administration and services; (c) Financial sector; (d) Business sector in wholesale and retail; (e) Fun and entertainment (movies, television, radio, music, theatre, etc.); (h) Health; and (i) others services. 
In most developed and developing countries, a growing proportion of workers are devoted to the tertiary sector. In the U.S., tertiary workers compose more than $80 \%$ of the labour force. The Law of Land Use of a city regulates where the urban activities can take place inner the city. When allow or nor certain activities in certain quarters, the law tries to give to the city a desired occupation. If the law does not impose restrictions to the busy area for the tertiary Sector and, it does not charge regulatory taxes for the land transference and building, the free market goes to function. In these conditions the income-producing activities, as of the tertiary one they go if imposing on less income-producing, or not income-producing as the housing. Gradual the not economic activities are banished from certain centres giving place to the sector of services. This sector needs centrality and also: (a) Agglomeration advantages; (b) Economic growths; and (c) Land Use Regulation.

\subsection{Concurrency Between Secondary and Tertiary Sector}

The tertiary sector is more dependent of central location, while the industrial sector is more ground dependent for the mechanised production. The industrial sector can be regional, national or international, in contrast of the retailing that is local. The conclusion is that the secondary sector searches the periphery, leaving free space in the centre for the tertiary sector, whereas the elementary school is basically agricultural. In the competition for the spaces, to if more valuing the ground for the increase of the demand in the points central offices, paid the activity of bigger return, in the case the tertiary one. In such a way the housing, leisure and small commerce go being banished of the urban centres. A social problem appear when the less gains, more far and expensive is do activities of work, leisure, etc. In case that it has not measured of control of the public power this comes to be a strong incentive to the in slums process (favelização).

\section{Spatial Dynamic of Land Use and Transportation}

The better way to understand and evaluate a transportation system is to know the spatial dynamic of land use and transportation (Fig. 5).

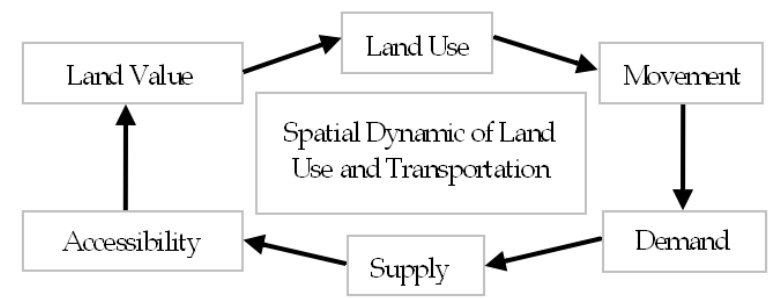

Fig. 5. Spatial dynamic of land use and transportation

The components can be described as: (a) Land Use - is understanding as a joint of activities realised, to live and work, fulfilling the necessities of food, live, generate exceeding to trade and then achieve the grade of auto-sustain. This role of activities can be classified in one or more of three sectors of the economies that will establish the dynamic of occupation and space utilisation. Each activity that takes place in an urban or rural space does demand movement that are derivatives of travel necessities to do business, work and play; (b) Movement - the movements that occur in one space are derivatives of an interrelationship 
between the role of complementary activities classified in: housing, work, business or a combination between them, involving bulk or passenger; (c) Transportation demand - the social economic activities get movement's necessity, which generates a demand for transportation systems until the desirable service could be reached; (d) Transportation Supply - can be viewed as a response of a physical or political environment to demand attempting and is related to initial conditions of regional supply of this facilities like rivers, sees, geography and whether, or some interventions that must be taking place by the man to provide the integration between regions and complementarities or trades; (e) Accessibility the supply of transportation systems generate facilities to feasible in one greater scale the intensity and diversity of land use, supplying not only the initial potential but creating news opportunities of use, differing some times absolutely of which that generates them; and (f) Land Value - increasing accessibility costs trade-offs decreasing transportation costs and increasing land value, changing the role of activities and creating new land use.

This new activities will taking gradually the spaces of older that will take place in another space or disappear of this region, turning goods or services incoming from another regions, establishing a new pattern of interrelationship between regions. This characterises the spatial dynamic of land use and transportation.

In Fig. 6 we see that this cycle of activities does not end. The changes in land use will create new patterns of movements that will demand new transportation systems, changing the land value, and so on.

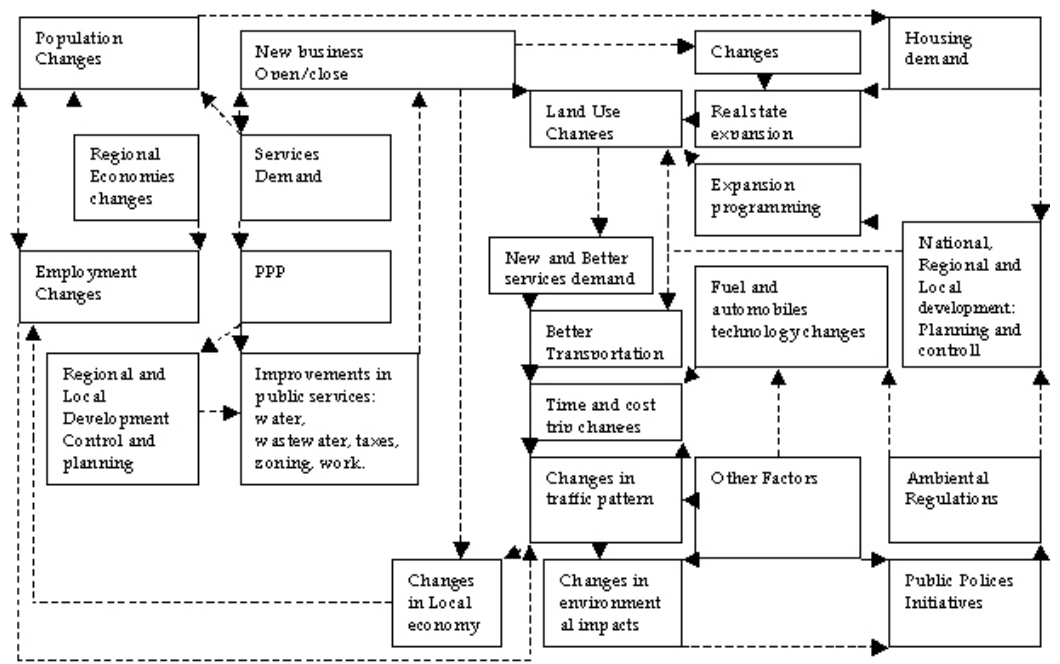

Fig. 6. Local and regional dynamic originated from relationships between transportation and land use

\section{Theory of Land-Use Transport Interaction}

Theories on the two-way interaction between urban land use and transport address the location and mobility responses of private actors (households, firms and travellers) to changes in the urban land use and transport system at the urban-regional level. That urban land use and transport are closely inter-linked is common wisdom among planners and the 
public. That the spatial separation of human activities creates the need for travel and goods transport is the underlying principle of transport analysis and forecasting. Following this principle, it is easily understood that the sub urbanisation of cities is connected with increasing spatial division of labour, and hence with ever increasing mobility. However, the reverse impact from transport to land use is less well known. There is some vague understanding that the evolution from the dense urban fabric of medieval cities, where almost all daily mobility was on foot, to the vast expansion of modern metropolitan areas with their massive volumes of regional traffic would not have been possible without the development of first the railway and later the private automobile, which has made every corner of the metropolitan area almost equally suitable as a place to live or work. However, exactly how the development of the transport system influences the location decisions of landlords, investors, firms and households is not clearly understood even by many urban planners. The recognition that trip and location decisions co-determine each other and that therefore transport and land-use planning needed to be co-ordinated led to the notion of the "land-use transport feedback cycle" (Fig. 7).

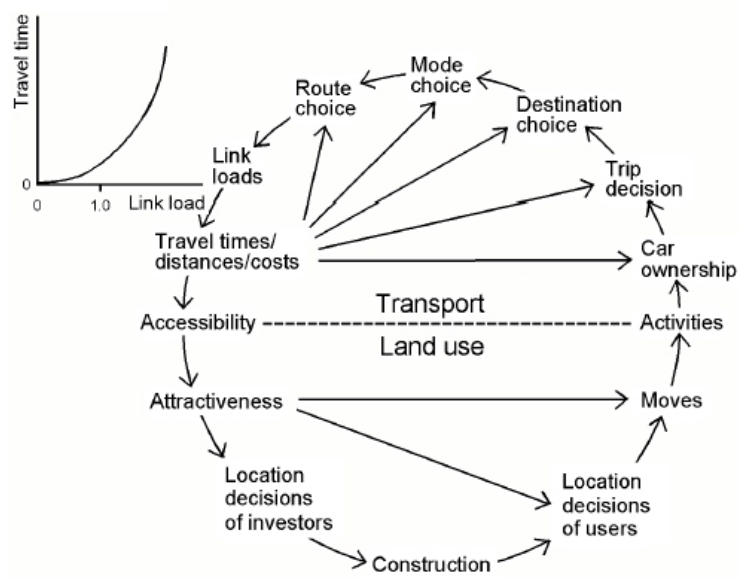

Fig. 7. The "Land-use transport feedback cycle" (Transland, 2000)

The major theoretical approaches to explain this two-way interaction of land use and transport in metropolitan areas include technical theories (urban mobility systems), economic theories (cities as markets) and social theories (society and urban space). A variety of 'ideal' land-use transport systems as optimal solutions to urban land-use and

transportation problems have been formulated since the late 19th century. These systems vary with regard to spatial structure, residential density, distribution of land uses and predominant transport mode. Attempts to determine the 'ideal' land-use transport system in contemporary cities have yielded different results. While it has almost become common wisdom that systems involving dispersed development are much less favourable with regard to average trip length, energy consumption, greenhouse gas emissions and land take, there is no unequivocal evidence for the advantages of either compact-city or decentralisedconcentration policies. The results of empirical studies of land-use transport interaction conclude that residential density has been shown to be inversely related to trip length (Transland, 2000). 
Centralisation of employment results in longer trips, while trip lengths are shorter in areas with a balanced residents-to-workers ratio. American studies confirm that attractive neighbourhood facilities also contribute to shorter average trip lengths. The theoretical insight that distance of residential locations to employment centres is an important determinant of average trip length has been confirmed empirically. The larger a city is, the shorter are mean travel distances, with the exception of some of the largest metropolises. None of the studies reported a significant impact of any factor on trip frequency. Residential and employment density as well as large agglomeration size and rapid access to publictransport stops of a location were found to be positively correlated with the modal share of public transport. 'Traditional' neighbourhoods showed a higher share of non-car modes. Accessibility was reported to be of varying importance for different types of land uses. It is an essential location factor for retail, office and residential uses. Locations with high accessibility tend to be developed faster than other areas.

The value of accessibility to manufacturing industries varies considerably, depending mainly on the goods produced. In general, ubiquitous improvements in accessibility invoke a more dispersed spatial organisation of land uses. Regarding impacts of transport policies on transport patterns, causal relationships are relatively undisputed, and empirical studies largely agree on the impact mechanisms. While travel cost and travel time tend to have a negative impact on trip length, high accessibility of a location generates longer work and leisure trips. Studies on changes in trip frequency are only known for travel time improvements, where time savings were found to result in more trips being made. Mode choice depends on the relative attractiveness of a mode compared to all other modes. The fastest and cheapest mode is likely to have the highest modal share. However, offering public transport free of charge will not induce a significant mode switch of car drivers, rather of walkers and cyclists.

\section{Review of Current Transport and Land Use Planning Issues}

The review covered both technical, behavioural and institutional issues, i.e. impacts of local land-use policies on the behaviour of travellers and, vice versa, impacts of transport policies on the location behaviour of households and firms within urban regions ('What'), as well as issues of co-ordination of land use and transport policies in different national and regional institutional contexts ('How').

Urban land-use transport models incorporate the most essential processes of spatial development including land use and transport. A number of integrated land-use transport models are in use today. There are significant variations among the models as concerns overall structure, comprehensiveness, theoretical foundations, modelling techniques, dynamics, data requirements and model calibration.

The transport sub models used in current land-use transport models do not apply state-ofthe-art activity-based modelling techniques but the traditional four-step travel demand model sequence (Ben-Akiva, 1974; Ben-Akiva \& Lerman, 1985; and Ben-Akiva et al., 1996), which is inadequate for modelling behavioural responses to many currently applied travel demand management policies. It is a limitation.

In the future, the integration of environmental sub models for air quality, traffic noise, and land takes and biotopes are likely to play a prominent role. Issues of spatial equity and socio-economic distributions are expected to gain similar importance in model building. 
Different policies affecting the location of workplaces including the construction of peripheral industrial estates and out-of-town shopping centres as well as an equal distribution of employment and population were investigated. It was found that decentralisation of facilities negatively affects the economy of the inner city while trip length and mode choice depend on the specific location and spatial configuration of population and facilities in the decentralised areas. When examining housing policies, neither the centralisation of population nor residential development in sub centres were found to have a significant impact on key transport indicators.

Land use planning policies have a major impact not only on spatial development but also on travel patterns. Development restrictions, e.g. a green belt around the city, can retard the sub urbanisation of population and workplaces thus strengthening the economy of the city centre. The construction of an outer ring road results in further decentralisation, relief of congestion and increasing travel distances. New public transport lines have little impact on location choice but tend to strengthen the inner-city economy. Introducing speed limits results in shorter trips and increased use of public transport. The effect of increased fuel taxes on the number and length of car trips is particularly strong. Significant fuel tax increases curb the further dispersal of residences and workplaces. Higher downtown parking fees generate negative economic effects in the centre and make out-of-town shopping centres more attractive. Public transport use free of charge reinforces a pattern of centralised employment and decentralised residential locations. Volume and length of car trips remain by and large unaffected by this measure. The ESTEEM study (1998) showed that the share of automotive travel in modal choice decreases with increasing size for cities above a threshold of 750,000 inhabitants. For cities below the threshold, a slightly positive relationship between city size and car use was found.

\section{Transportation Planning}

Urban and regional transportation planning process is very important because turn land use sustainable. The transportation planning process will generate a legislation allowing monitoring and control land use as it was planned. A sustainable development can be defined as the development that assures the satisfaction the needs of population, without jeopardising the capacity of the future generations to satisfy the own ones: (a) To assure that the standard of life (rent available) of all the inhabitants surpasses the survival threshold; (b) To assure a good quality of life to the population, as far as access to basic grants and rights (education, health, environmental quality, historical patrimony, house, etc.); (c) To assure the equality opportunities, the right to the own culture and the rest of fundamental rights of the person; and (d) To promote that the obtaining of a certain level of development for the present population does not imply to subordinate that the future inhabitants cannot accede to resemblance or better levels of development and, in particular, to assure that the natural and cultural patrimony is not reduced.

In order to grant sustainability in the development processes it is essential: Information, awareness, commitment and public participation in the fixation of objectives and activities, and in the co taking responsibility in the profit of those with the materialisation of the same. It interesting at this point present the differences between growth and development: (a) Growth - the concentration is over the quantitative increases of different social variables; and (b) Development - it implies the improvement of the "standard of life" and of the 
"quality of life" of the people. Therefore, not only it incorporates aspects of quantitative nature, but essentially of qualitative nature.

There is a creation of sustainability when promoting the integration of transport and land use planning. Three main dimensions of comprehensive sustainability which cannot be seen in isolation are identified: Environment, Society and Economy. Economic efficiency is one part of the sustainable triangle (Fig. 8) and it will be influenced by integrated land use and transport patterns. The integrated approach of Transland mainly targets on creating spatial urban patterns as well as transport patterns which fit into these spatial structures in order to ensure the development of sustainability.

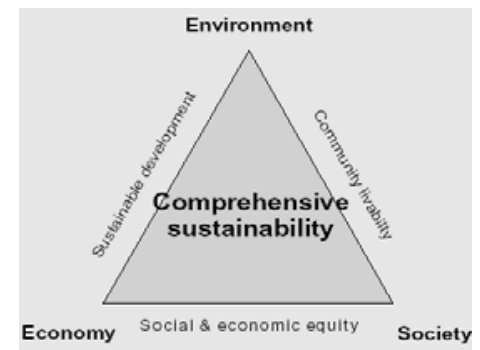

Fig. 8. Sustainable triangle (Transland, 2000)

The "Developing the citizens network" (1998) by the EU sets practical methods for making transport systems more sustainable and shifting away from excessive dependency on private car use: (a) Raising the quality and accessibility of public transport services; (b) Making walking and cycling more attractive; (c) Reducing the demand for travel, for example by reversing the trend of dispersing of functions to places which are hard to reach except by car; (d) Removing psychological barriers to the use of alternatives to cars and winning public support for policies to encourage more use of these alternatives; and (e) Making transport an essential component to strategies of spatial planning (Williams, 2005). The integration of land use and transport planning can only provide a partial contribution to the implementation of sustainability, with impact on sustainable development within the areas of ecology, economy and society. An integrated planning approach develops structures in which ecological, social and economic sustainability can be promoted. Two basic strategic goals can be identified: (a) Land use goal - "fulfilling land use needs occupying fewer space in a better way"; (b) Transport goal - "fulfilling travel needs through environmentally friendly modes".

Sustainable mobility can be achieved considering the following chain of goals/actions: (a) Improve accessibility and the use of the space; (b) Increase the environment-friendly modes share (public transport, cycling, walking); (c) Reduce congestion; (d) Improve safety; (e) Reduce air pollution, noise, and visual nuisance; (f) Developing and maintaining a wealthy and healthy urban economy; and (g) Ensuring social equity and transport opportunities for all community sectors.

Diagnostics consists of a check-up, or evaluation of traffic and transportation existing systems including traffic generation hubs: housing, shopping centres, economic activities, etc. The planning starts with a data collection and a diagnosis of all existing transportation systems and zoning legislation. Planners will be able then to design the new pattern of land use according with the existing and future infrastructure. 


\section{Transportation Planning Process}

A Systematic view of a transportation planning process can be explained in a simple steps as follows: (a) Determining the study area; (b) Establishing of desirable transportation and traffic conditions in the year project; (c) Determining existing studies and planning; (d) Check up of actual situation; (e) Determining actual flow pattern on the multimode transportation network; (f) Evaluation of network capacity and reserve to future projected demand flows; (g) Proposals of improvements and magnifying and implantation of transport subsystems; (h) Plan review; (i) Master plan; and (j) Indication of the financing sources. All areas of performance are described in the next section.

\subsection{Transportation Planning - Areas of Performance}

Urban Transportation Planning perform transportation systems conception as a hole, starting from a transportation demand forecasting and the development scenarios definitions of transportation systems. The transportation engineering performs a tools development to organise city traffic so that the planning process turn effective. The management and operation of public transportation systems perform procedures to grant the functionality of public transit systems and manager the system to achieve the desired goals and objectives reflected by operational performances of such systems. The transportation network modelling is commonly represented by graph theory and network theory for system modelling and analyses the flow distribution in a transportation network. Some examples of network analyses are: CTA Project (by Area Traffic Control - Transyt); and Transcad-GIS-GPS (http:// www.apontador.com.br; Googlemaps).

\subsection{Common Transit and Transportation Systems}

Improvements in transportation have created a major change in the location of cities, but the connection between transport technologies and the internal structure of cities is at least as large. Traditional European towns were built for people who got around by using their feet. These cities were extremely dense. Generally homes and jobs could not be further apart than the distance that could be covered on foot. Markets also had to be small and local. The rise of public transportation permitted a change in urban form. Buses and subways still mean that people need to live in dense areas, but there can be much greater distance between home and work. After all, public transportation is a very time intensive technology. People don't want to get on a bus every time they have tea with a friend or go to the market. However, they will spend significant time periods getting to work. A typical bus or car city is a dispersed high-density city. The Brazilian Favelas are a perfect example of these phenomena. They are high-density areas that permit walking as a means of locomotion, but they are linked to employment by public transportation routes. Generally small busesjitneys - permit these poorer Brazilians to get to their jobs.

American edge cities-suburbs with major employment centres-are cities designed exclusively around automobiles. These cities require not just one car in every garage, but several. Each mobile member of the household must have their own car to do anything. These cities are built at much lower densities. Driving three or four miles to the nearest grocery store is not, after all, a hardship. At their best, they offer lower density living with quick access to jobs and shops on relatively empty roads. While many academics find the suburban lifestyle sterile, there is no question that consumers who can afford it appear to greatly enjoy its many amenities. Within the U.S., the walking cities of the 19th century were 
gradually replaced by the public transportation cities of the early 20th century. By 1900, less than $7 \%$ of Americans used public transportation to get to work. Since 1950, America has seen a dramatic sub urbanisation of first people and then jobs. The typical job is now far from the city centre and the typical person lives even further out. As result, Americans consume unbelievably large amounts of housing relative to almost any other country.

Why don't more people in the U.S. use public transportation? Public transportation, despite its widespread availability in many cities, is used only by the poorest Americans outside of a few large cities. The reason for this is that public transportation is an extremely expensive technology for the average user-when cost is measured properly, including the opportunity cost of time. Commuting times for public transport users are much higher than commuting times for drivers. This time cost comes primarily from the fixed time cost of public transportation - this is the cost of getting to the pickup spot, waiting for the bus or train, and getting from the drop-off spot to the final destination.

Few other countries have fully followed the American example, although Canada and Australia probably come closest. European countries have massively taxed gasoline and massively subsidised public transportation. The impact of this has been to stop European cities from evolving towards car-oriented places. Latin American cities have not fully followed the U.S. model because automobiles remain too expensive for the vast majority of citizens. Will Brazil move towards the American edge city model? It seems likely that Brazil will continue to get richer. If this process continues then it seems almost inevitable that car ownership will rise significantly and urban land use patterns will start to come closer to the U.S. model. There are two potential barriers to this transformation: increasing gas prices and government regulation. Some experts believe that increasing use of fossil fuels will push the price of gasoline up many times. The historical record suggests that high prices will tend to create striking technological responses. In the short run, higher prices will be offset by conservation technologies (more efficient car engines). In the long run, higher gas prices will be offset by alternative fuels with can also power cars (like ethanol in Brazil). The probable hypothesis is that cars will remain cost effective even as fossil fuels get used up. Government regulation is of greater concern, especially in the short run. European countries have created an entirely different urban landscape than the U.S. through their different gas taxes and public transport policy. Brazil can, in principle, follow this course and keep cities dense and focused on buses, surface light rail (tram and streetcar) and subways.

One possibility is put taxes on certain types of drivers but a biased government policy against cars and car cities is contrary to the principles of economics. While the government certainly has no obligation to subsidise the car, economics tells us that consumers are better judges of what makes them happy than governments. Even if some urban analysts dislike the world of suburbs, it seems like an outrageous piece of governmental restriction on freedom to try to deny consumers their ability to choose how to live and how to commute.

To planning the general network that will supply the necessities for desired and planned land uses pattern, for a determined region, the planners usually utilises a methodological well know tool called Four Step Method: (a) Trip Generation - provides the linkage between land use and travel patterns. Existing land use and travel are linked utilising techniques such as cross-classifications, trip rates or regression analysis. These relationships are then applied to estimate future travel based on the forecasted change in land use; (b) Trip Distribution - is the process of distributing the trips generated in each zone to all the possible destination zones available. As in trip generation, there are several types of models 
for accomplishing this: growth factor models, intervening-opportunity models, and gravity models. In the gravity model, the number of trips between two zones is directly proportional to the product of the number of trips produced in one zone and attracted in the other, and inversely proportional to the degree of separation between the two zones, represented as a function of travel times; (c) Modal Split - is the process of assigning persontrips to available modes of transportation. There are three major factors that need to be considered in this analysis: characteristics of the traveller, characteristics of the trip, and characteristics of the transportation systems. The types of techniques that have been used in the development of modal-split models include regression analysis, diversion curves, and cross-classification. A different modelling approach is also utilised that consider the probability that an individual will chose a particular alternative is a function of the characteristics of the individual and of the overall desirability of the chosen alternative relative to all other alternatives, and (d) Traffic Assignment - constitutes assigning the distributed volumes of trips, by mode, to individual network links. The basis for this assignment procedure is that the choice of rout is basically a decision to minimise total travel time through a transportation network. There are several techniques that can be used in the assignment procedure: minimum path, minimum path with capacity restraint, multiroute probabilistic assignment. All have this basis for this operation.

\subsection{Desirable Transportation System Characteristics}

Starting from the zoning plan is possible to determine all desirable characteristics to the news transportation systems that must be supplied in each stage of the development process as: (a) Road Hierarchy - road system must be designed in agreement with the road hierarchy, establishing curbs, grades and width in accordance of designed vehicle to each urban and rural area geometry (lane width, parking designs, bikeways, sidewalks cross walkers, structural, arterials, collectors and local streets). A transportation system must be put together with another systems and designed itself in a hierarchical way (Green Book, 2004); (b) Mobility/accessibility - this structure contrast mobility with accessibility and has inverse interrelationship. Local systems must be high accessibility and low mobility wit low speeds, collecting and distributing people and goods to arterials systems that must have low accessibility and high mobility. Street networks connecting the remain of the city by collectors and arterials, considering distances between them like: Arterials major $-6 \mathrm{~km}$, Arterials minors $-2 \mathrm{~km}$, Collectors $-1 \mathrm{~km}$, and Locals -100 to $200 \mathrm{~m}$. This systems must preserve the roads connectivity providing binaries systems always as possible; (c) Inter modality and terminals integration - the systems must be integrated itself, across common terminals or at least closets ones, to perform a high utilisation of each vocation and capacity; (d) Traffic Calming in local areas - the people must walk safe, comfortable, without noise; and (e) Grade separation evaluation in all collector-arterials intersections - the lost time must be minimised with the adequate design and continuous evaluation of grade separations in each intersection.

\section{Transportation Demand Forecasting}

Knew as allocation models: (a) Network modelling using graph theory; (b) Determine the shortest paths; (c) Network traffic loading; (d) All or Nothing allocation model; (e) Stochastic models; (f) Capacity constrained models; and (g) Network equilibrium models. 
These models are very complex and utilise mathematics techniques to mitigate a system optimised traffic pattern in the entire network. The allocation process needs data like origin/destination by transportation modality. This flow separation by different modes is performed with use of modal split techniques. This kind of models consider characteristics of transportation modals and vehicles, and user characteristics like: trip motivation, income, age, sex, etc. Then is possible estimate how transportation flows split between modes. The results are then loaded into matrices origin/destination O-D. These matrices are estimated by trip distribution models utilisation.

This stage require data like number of trips living each zone an arriving in each zone, well like trip cost, measured by time, distance, etc., between each pair of centroids. Trip generation is defined as the estimation of a number of people living and entering a specific traffic zone by interval of the day and trip motivation. In order to build these models is necessary information about socio-economic level of population and what kind of activities these people realises. Is also necessary to get demographic data and to perform one analyses of distribution of peoples like where they live, work, play, buy, etc. Then, is necessary to perform a study of land use and, urban activities and determine how and where the urban equipment are located: schools, work, shopping, others.

Figure 9 shows the hierarchy of studies levels to approach transportation problems. So, considering local problems, the problem abroad is inner a greater system. When approach a local problem is important to see that this problem can be inserted in a bigger one and then, must be analysed in a major level of planning.

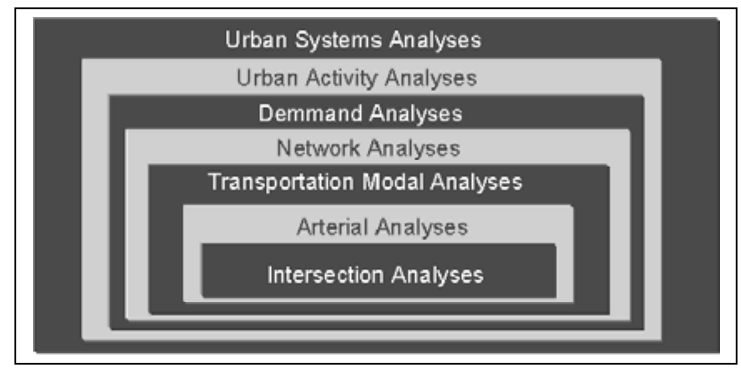

Fig. 9. Hierarchy of transportation planning system check-up

\section{A Traffic Problem}

The traffic problems must be approached, for example, as a problem that could be solved with local interventions, like: (a) Signalisation on street; (b) Light signals studies; (c) Traffic and pedestrian counting; (d) Phases definitions; and (e) Phases calculating (Fig 10).

The study can indicate physical changes like changes in sidewalk design or the necessity of grade separations intersections, separating flows at different levels. The problem analyses can indicate that local changes are ineffective to the problem solution and that is necessary an arterial intervention that can include: (a) Parking control at long of way; (b) Control access; (c) Speed limit control and green wave studies for transit; (d) Physical changes in arterial level; (e) Turn arterial cross section greater or smallest; (f) Duplication; and (g) Different levels intersections (Fig. 11). 

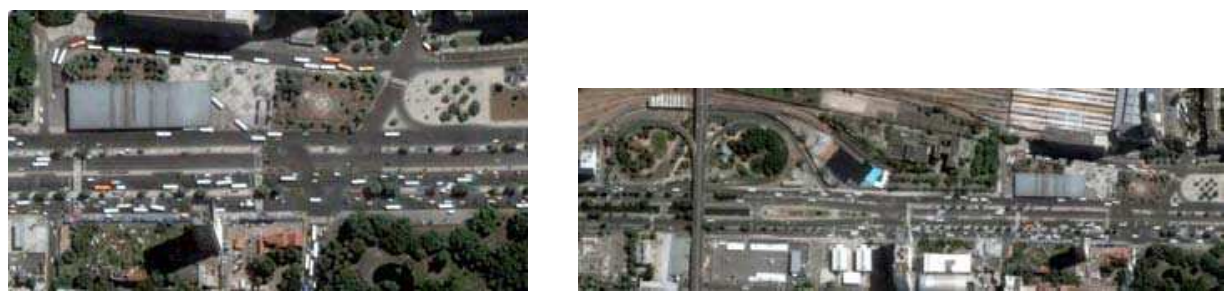

Fig. 10 and 11. Node from an arterial, and arterial presented as a set of nodes and links

The problems can be greater in hierarchy like an intervention in arterial system couldn't solve the problems by itself, being necessary to perform a network analyses. In this case the traffic pattern on network is studied, and the network interventions must be done.

The urban network analyses start by defining the study region that is then divides in traffic zones (Fig. 12). This is necessary because is impossible to approach a continuous region but divided in traffic zones to be able to apply the well know models. After zoning, a hub is attributed in each zone. The models consider that each traffic is generated/attracted in hubs. The data base must contain points of origin/destination of passenger cars and transit, network design, volume, capacity and link controls, bus lines and its stops, frequency and vehicle capacity, the model is applied to estimate the pattern of traffic flow over the network, between each origin/destination hubs. By the results the annalist must determine: (a) Street changes; (b) Changes in bus lines; (c) Exclusive and priority lanes; (d) Building of bridges, tunnel and other facilities; and (e) Metropolitan subway construction/expansion.

Figure 13 shows the macro area to be analysed.
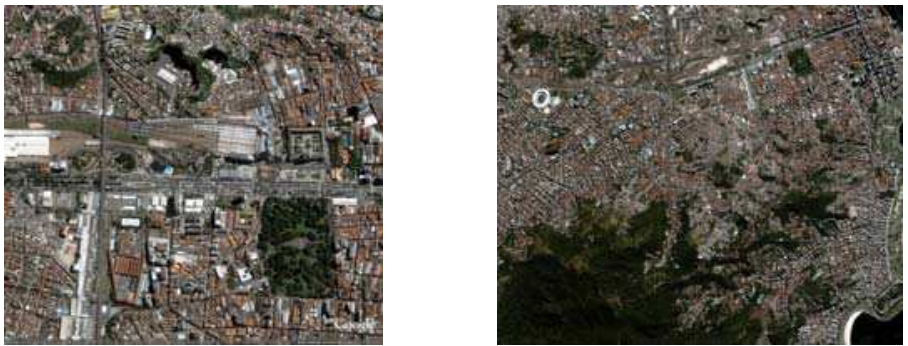

Fig. 12 and 13. Zone and original arterial, and macro area to be analysed

\section{Transportation Demand Analyses in Urban Areas}

In Transportation Planning is very important consider that: "The transportation is a mean activity utilised to achieve an end activity". The trips are realised to enable the realisation of activities in a space separated equipment. The main question is to assure the realisations of activities. The transportation and urban systems must, in an integrated way, services to this goal. It can be achieved with an integrated urban planning that must include: (a) Land Use Planning; (b) The acts over urban activities; and (c) The acts over the transportation systems. There is a natural market failure in the transport sector. Individuals who commute to work don't internalise the effect that their commuting decision will have on other commuters. Every driver imposes a cost on every other driver. This means that too many people use the 
roads especially during peak hours. As long as roads are publicly managed (which is not necessary-private roads are a real possibility), this calls for a policy response. The best policy responses to the congestion externality all use the price system. Because the market failure is that drivers don't pay for the congestion they create, the best policy response will be to create tolls, or other charges that make them pay for this congestion. One price system response to congestion is a standard road toll. Ideally, these tolls will differ by time of day to reflect the different level of congestion on the road over time. Modern transponder technology means that highway tolls can be collected quickly and efficiently. In dense city streets, highway tolls will be harder to collect. In these cases, an approach like cordon pricing is generally more effective. Cordon pricing works by charging drivers to use city streets during peak time periods. One way of implementing this technology is to make drivers pay on a monthly basis for the privilege of using city streets during peak hours. Drivers then display a sticker in their window to show that they have paid the toll, and drivers caught without this sticker must pay a fee. This type of cordon pricing has been used in Singapore and elsewhere effectively. Non-price controls are almost always much less effective and more costly socially. An example is the control based in car license that restrict some cars from driving on some days. License plate numbers are used as a means of determining who is allowed to drive on which day. These proposals are inefficient because they imply that a major part of the automobile stock must lay idle for one day. Furthermore, they don't allow the people who would particularly want to drive on that day to drive even if those drivers would happily pay for the social cost of their driving. For much of the population, these car-based approaches are fairly irrelevant since they use public transportation. For this group, the key to faster commute times is improving public transportation. In general, the economic literature on public transportation has been quite clear. Buses are much more efficient than trains or subways for intra-city transport. Instead of extremely expensive extensions to the subway system, minor subsidisation of the bus network will reap much more beneficial results. In cases where traffic is extreme, it may even make sense to build tunnels for buses to drive under ground. In general, subways are almost never cost effective and sold to the public on the bases of vastly over-inflated rider ship estimates. They are particularly inefficient for cities like São Paulo or Rio de Janeiro.

\section{Transports and Urban Activities - The Demand for Density}

The defining characteristic of cities is density - the physical proximity of people. People come to cities and pay the higher costs for urban land because they want to be close to other people, or to other resources in the city. Economists think of the advantages of cities as coming from the elimination of transport costs for goods, people and ideas.

Physical proximity facilitates the interaction of economic actors. As such, the location and structure of cities is intimately linked to transportation technologies. The growth and decline of cities over time tends to be closely linked to changes in transportation technologies. Over the past 100 years there has been a massive improvement in transportation technologies that have greatly changed the urban landscape. In this section, I review the impact of improvements in transportation on the location and structure of cities. First, I review the impact of improvements in inter-urban transport technologies. Second, I review the impact of changes in intra-urban transportation. The inherent desire and need to perform different activities at different places implies a need for travel in any society. 
The crucial planning challenge is to arrive at an optimal spatial organisation of activities (maximising opportunities) and a well balanced transport network linking these activities in an efficient and sustainable way. Therefore, land use and transport planning are highly related by nature. Finding the right balance is a delicate task in urban areas especially, with their complex activity patterns and their evident spatial and environmental constraints. Travel patterns of persons and goods are the results of equilibrium between preferences of people and companies (travel demand) and the travel conditions resulting from the supply of transport facilities and spatial patterns of activities. These preferences and conditions will determine the travel choices with respect to trip distances (distribution), mode choice and time of travel. The relation between transports and urban activities measures the specific activities and equipment distribution. Considering the activities versus required equipment, we have: (a) Work; (b) Studies; (c) Shopping; (d) Private questions; (e) Business; and (f) Play. The distribution of land uses (residential, industrial or commercial) over the urban area determines the locations of human activities such as living, working, shopping, education or leisure. The distribution of human activities in space requires spatial interactions or trips in the transport system to overcome the distance between the locations of activities.

The distribution of infrastructure in the transport system creates opportunities for spatial interactions and can be measured as accessibility. The distribution of accessibility in space co-determines location decisions and so results in changes of the land-use system.

Considering commuting as a mean to an end, transportation facilities can be viewed from the logic presented in Fig. 14.

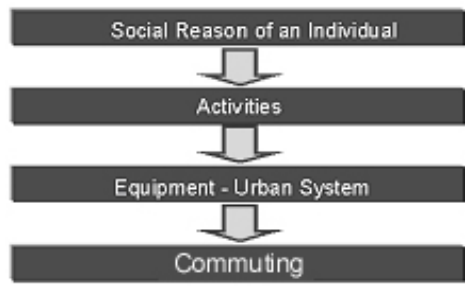

Fig. 14. Transportation facilities as a mean to an end

The society attributes to each person one status express by main activity like work, study, etc. With this attribution people have the alternative run a set of activities. By activity, we understands that's, related with urban equipment. Live, work, buy, etc., are sets of activities realised in appropriated locals like farmers, offices, industries, universities, that here are calling urban equipment. The equipment, proper to different activities, are dispersed in the urban area, and separated by variables distances. Transportation vehicles cover such distances in general. The change of activity, during the day, implies in change of the equipment and commute, covering a distance between both. The necessity of play an activity is the cause and the commute is the effect of activity played.

The social reason can be defined from the following social characteristics: (a) Age; (b) Sex; (c) Occupation; (d) Income Level; and (e) Qualification Grade. In Transportation Demand Analyses are important the characteristics that will impact individuals activities pattern and them in the number of commutes. The social and cultural environment must be taken in account. As example, in the most cultural developed countries a lower class of people goes more to theatre than in development ones. Table 1 shows an example of potential activities distribution of each social group. 


\begin{tabular}{|l|c|c|c|c|c|c|}
\hline $\begin{array}{l}\text { Activity I } \\
\text { Group }\end{array}$ & Work & Studies & Shopping & Privete & Business & Fun \\
\hline Workers & $\mathrm{X}$ & & & $\mathrm{X}$ & $\mathrm{X}$ & $\mathrm{X}$ \\
\hline Studants & & $\mathrm{X}$ & & & & $\mathrm{X}$ \\
\hline $\begin{array}{l}\text { In House } \\
\text { Workers }\end{array}$ & & & $\mathrm{X}$ & $\mathrm{X}$ & & $\mathrm{X}$ \\
\hline Pensioners & & & $\mathrm{X}$ & $\mathrm{X}$ & & $\mathrm{X}$ \\
\hline
\end{tabular}

Table 1. Example of potential activities distribution of each social group

For transportation demand analyses is important the following characteristics of activities that turn possible deduct demands forecasting of urban transportation: (a) The kind of activity will define the equipment used and then the place or city zone that will be the destination of one displacement; (b) The moment that one activity starts will define the end of a trip; and (c) The duration of such activity will define the starts of back trip.

The sets of activities that one can do, function of your status, is an ideal pattern or potential but, the supply of equipment and transportation that city can supply will imply in constrains in the standard of activities. There is constrains imposes to a sample of activities of each people, it is function of the distribution of equipment and because transportation systems. Each people have stock of time, money, and credit, physical, psychological, etc. Each activity imply in a consumption of this stocks to run the activities and to get the displacement necessary between them. Each people solve your diary schedule problem following the rule: "Realise main activities first and, the less important activities with the surplus stocks". In this way, the potential sample of activities is reduced to a real sample.

Considering the interrelationship between activities and equipment distribution in an urban area, we conclude that a special fact in a demand analysis is that living is the basis of urban activities. It is the origin and destination in almost all commutes.

Table 2 shows that home is the origin of 15,826 commutes. Then, to estimate the transportation demand is important the knowledge of equipment distribution with respect a living areas: relation home-work-home. For example, in the city of Rio de Janeiro this relation is about $97.4 \%$ (PDTU, 2001).

\begin{tabular}{|l|r|r|r|r|r|r|r|r|r|}
\hline O/D & Home & Work & Studies & Business & Fun & Private & School & Other & Total \\
\hline Home & & 3,430 & 2,727 & 365 & 504 & 283 & 347 & 320 & 7,976 \\
\hline Work & 3,308 & 66 & 67 & 17 & 13 & 8 & 150 & 9 & 3,638 \\
\hline Studies & 2,730 & 26 & 42 & 5 & 16 & 4 & 137 & 15 & 2,975 \\
\hline Business & 366 & 3 & 1 & 5 & 12 & 7 & 12 & 6 & 412 \\
\hline Fun & 516 & 5 & 1 & 5 & 21 & 4 & 20 & 5 & 577 \\
\hline Private & 268 & 9 & 2 & 7 & 5 & 11 & 25 & 5 & 332 \\
\hline School & 357 & 154 & 136 & 5 & 18 & 22 & 42 & 28 & 762 \\
\hline Other & 305 & 7 & 8 & 6 & 13 & 3 & 30 & 8 & 386 \\
\hline Total & 7,850 & 3,700 & 2,984 & 415 & 602 & 342 & 763 & 396 & 17,052 \\
\hline
\end{tabular}

Table 2. Matrix with number of daily commutes generated from equipment of each row in the matrix and with destination to equipment in each column 
Also, it is important to analyse each particular activity, the distribution of equipment to your utilisation and the characteristics that will impact the transportation demand: (a) Work - if a person works, this is a mainly activity to him. Characterised by economically active people. Highly stability in time with well knows duration, originating pendulum demand in transportation systems, with two peaks a day, in the morning and in the afternoon. There is a functional division in land use. The secondary sector is located in the border and the tertiary sector in the centre. This classification is fundamental to estimate where some activity will take place; (b) Study - mainly to a class of population. Must have a near distribution house-schools, mainly in the first grades. The last grades can be centralised. It can be classified in: Primary, Secondary, Technical, Graduation, and Post-graduation; (c) Shopping - diary supply of general goods. Housewives in general have this responsibility, which can be spread in diary, weekly, monthly. The equipment to daily shops are delivered around the city overall. This contributes to commute by walk. The equipment to buy goods at meddle and long run are sparse and located in the centre of the cities. They demand transportation systems in commutes. The distribution of equipment to diary buyers is function of several factors, like: structure of the city, population density, age of neighbourhood, and social structure of demand; (d) Private questions - several activities related with tertiary sector. No working or shopping include in this category; (e) Public services; (f) Private services - located generally in centre areas; (g) Business - activity interrelated with the job. In general is inside tertiary sector. Have a trend to be located in the central areas. Consist of private or public administration; and (h) Fun - activity played at a free time. Theoretically all peoples have time to play fun activities. The kind of fun depends of status (level of income), local culture, etc. Supply equipment is determinant. Cultural factors are determinant to intensity of activity. It is important to transportation differentiate the weekend fun from in the others days of a week, because the standards are different.

\section{Characteristics of Urban Structure and Plans}

There has been a remarkable revolution in transportation technologies. In the early 20th century, inter-city transportation was still very much dominated by water born transit. Gradually rail and then trucks has substantially reduced the costs of moving goods across space. These costs have also eliminated the advantages of locating near natural resources, including water and farmland. As a result, cities built around production have gradually been replaced by cities built around consumer and political advantages. In the early 20th century, intra-city transportation was dominated by walking. Over the 20th century, first rail, then buses and cars have gradually come to replace human legs as the primary form of locomotion within cities. As a result, the walking cities of 1900 have gradually been replaced by driving cities of today. These rapid structural changes have created major policy problems. People have left agricultural areas and crowded into cities. In those cities, they increasingly use cars and buses instead of their feet. As a result, traffic congestion has grown more and more sever. In Brazil, commuting times in the largest cities frequently exceed more than two hours annually. This implies that there is a huge share of national resources being allocated towards the process of getting to work and getting around the city.

The Managing Plan appears of the necessity of auto-sustainable development of the city, and as legal necessity (Constitution). To analyse existing conditions and trends; to idealise future conditions; to delineate politics and lines of action for implementation. A managing 
plan identifies and analyses Inter-relations between obligator and optional elements. They are obligator elements: transports, housing, economy, environment, public land use, spaces, and natural areas of protection, threats and agricultural and industrial areas. They are optional elements: urban project, public security, and cultural resources. There are some elements necessary for the preparation of the Managing Plan, like: (a) Existing land use residential, commercial, industrial, institutional, public spaces, strips of land, agricultural area; (b) Transports - urban mesh, capacity of the mesh, volumes of traffic, offers of areas of parking and demand, stations of public transport for way, bikeways networks, sidewalk networks, maps, plants, networks of public services population and job, local economy; and (c) Special topics - historic site, archaeological, farms, etc.

The element land use in the Managing Plan presents the general distribution, localisation and characteristics of the land use present and future. Maps of future land use: they present the supply to infrastructure necessities. The element transport in the Managing Plan presents the circulation of the traffic, transit, bikeways, ports, airports, tourist railroads, routes, lines of desire of pedestrians and parking. The proposals for the systems of municipal transport must consider the plans of state and federal transport and must be integrated in these systems. It evaluation offers existing facilities and the future adequacy in capacity terms and modality, considering the regional characteristics. Plans of transports are originated from the Managing Plan and developed using the knowledge of the process of transportation planning. Systems of effective transports are basic for the maintenance of the productivity, comfort, health and security of communities and regions. A plan of transports establishes a chronogram physicist-financier to provide mobility, accessibility, security, economy and necessary quality of life to community.

There are some reasons to elaborate a plan of transports: (a) Management of existing systems; (b) Continuity of investments in existing projects; (c) Existing Realignment of services; (d) Introduction of new services; (e) Construction of new facilities; and (f) Identification of the sources of financing of existing systems and improvements.

The plans of transports vary in boarding, content and target in accordance with the space and the time that treat. Five basic types exist: Federal plans, State plans, Metropolitan plans, Municipal plans, and Zone plans. These plans must involve the: Ministry of Transports, State secretariat of Transports, Metropolitans Secretariat of Transports, City department of Transports, Representatives of the Confederations of Public Transporters, Regulating agencies, and Representatives of the communities.

Six steps exist in a development of the plan of transports: evaluation of the capacity of the system, deficiencies and necessities, establishment of goals and objectives, to define and to prioritise future necessities, to develop, to evaluate and to select potential solutions, to prepare and to adopt the plan, including public revision and comments, and finally to implement, to monitor and to evaluate the performance of the plan.

The process of planning can be condensed in four elements of a backward-fed cycle: (a) Planning of system - demand for trips evaluation of market, differentiation of market planning of service, allocation of trips/modal choice; (b) Planning of service - frequency, capacity, quality; (c) Implementation of service - fleet of vehicles; and (d) Periodic revision. Legal aspects must be considered, such as: legal legislation of existing land use, law of zoning, Constitutional law. The urban planning and the subsequent process of intervention must consider the systemic interrelationships and the hierarchy of the components. 
The relations between transport and land use generates a process that must be monitored and controlled. All solutions must be verified, the foreseen impacts and its minimised effect. Users must always be the targets of a plan. Users' attention must be raised to make them interested in working for their district, to accept disturbance which cannot be absolutely avoided in densely mixed used areas, and to be prepared to reduce travelling by car. Network of citizens associations are a good mean of public participation. Public involvement, when properly raised and organised, is a viable and desirable addition to the decision making and implementation process. Preliminary studies can help the project.

A large-scale urban project should be managed on a long-term basis and the contracting authorities must play a leading role in deciding what work has to be carried out by the partnership responsible for implementing the project and then assessing the actions according to a clearly defined framework. It is essential that at the start of the project, the authorities carry out preliminary studies to effectively define all aspects of the project.

In developing large-scale developments, it is important that local authorities work as part of a 'development team'. Therefore, all professionals (architects, developers and planners) should work together and consult with each other.

The end result should be for the general public to be able to live with the different professional viewpoints and therefore for the views not to be extreme. In planning a largescale development, even the early inhabitants should be offered the most important infrastructures for supply, education, leisure, and public transport connection in order to give them the immediate possibility to reduce their need to travel by car. The concept of sustainability as well as ecology is feasible in a large context such as building a new district.

\section{Land Use and Transport Polices}

The impact of high residential density in reducing average trip length is likely to be minimal in the absence of travel cost increases, whereas a high density of employment is positively correlated with average trip length. Attractive neighbourhood facilities can be seen as a 'pull' factor for reducing trip length. Since more peripheral locations usually have longer trips, trip length can be expected to be negatively correlated with city size. Little or no impact on trip frequency is to be expected from land-use policies according to the theory of fixed travel budgets. Residential and employment density as well as large agglomeration size and good public-transport accessibility of a location tend to be positively correlated with the modal share of public transport, while neighbourhood design and a mixture of workplaces and residences with shorter trips are likely to have a positive impact on the share of cycling and walking. The impact of transport on land use is mediated by a change in the accessibility of a location. Higher accessibility increases the attractiveness of a location for all types of land uses thus influencing the direction of new urban development. If, however, accessibility in an entire city is increased, it will result in a more dispersed settlement structure. The impacts of transport policies on transport patterns are clearer and stronger compared to the interplay of land use and transport. While travel cost and travel time have a negative impact on both trip length and trip frequency, accessibility has a positive impact on both. Mode choice depends on the relative attractiveness of a mode compared to all other modes. The fastest and cheapest mode is likely to have the highest modal share. In general, the theoretical considerations support the conclusion that the 
impact of 'pull' measures, i.e. land use measures, is much weaker than the impact of 'push' measures, i.e. increases in travel time, travel cost etc.

Due to their complementary effects, land-use and transport policies need to be combined. The combination is important to achieve synergetic effects. This refers to the relationship of investment and services and planning on the one hand and regulation, pricing and to a certain extent information on the other hand. Planning and investment policies are the most important means to reduce the need for travel, because they influence land-use and transport and represent an important pre-condition for reducing travel distances and land take and making efficient use of the transport infrastructure (pull effect). Their successful implementation is only possible if additional pricing and regulatory policies create the necessary incentives for these changes in behaviour (push effect).

Co-ordination and integration of transport and land-use planning contribute to reducing the need for travel and making the remaining traffic sustainable in the institutional and policy dimension. Co-ordination includes institutional potentials, and integration encompasses policy-related potentials. Policies in the area of land use aim at reducing the need for travel, as they primarily affect urban development and land use and therefore contribute to a reduction of distances. Transport policies aim at making the remaining traffic sustainable, as they primarily influence the travel behaviour and energy efficiency of transport. However, this analytical distinction becomes somewhat blurred in practise, especially in the long run, because transport policies as a secondary effect influence land use as well, for instance where pricing policies such as fuel taxes increase the tendency that people move closer to their work places or to the urban centre to save travel costs. There are several regulations instruments for land use and transportation. Restrictions of access to the centre and creation of radial systems of collective transport of mass: (a) Solution adopted in the Europe in years 50 and 60 and later in Latin America, following the same logic of preservation of the tertiary sector in the economy; (b) Reduced trip length; (c) Reduced trip times; (d) Increased public transport patronage; (e) Increased multimode trips; (f) Increased ratio of off-peak to peak travel; (g) Increased incidence of cycling/walking; (h) Reduced rate of increase of passenger $\mathrm{km}$ travelled on roads; (i) Reduction in energy used by the transport sector; (j) Reduced emissions from vehicles; (k) Reduced noise exposure; (l) Capitalisation in home/office values; (m) Attraction of new business; (n) Employment; and (o) User/citizens satisfaction.

\subsection{Planning Co-ordination}

Planning co-ordination is complex due to the different relevant spatial levels (local, regional, national), the different sector policy fields involved and the variety of public and private actors and stakeholders involved. Institutional barriers and insufficient planning regulation and procedures are likely to be partly responsible for the uncoordinated and fragmented current planning practice. Further deregulation and liberalisation can intensify this coordination problem. The momentum of market forces will become increasingly important, and will impel a fundamental consideration about the future role and legitimacy of proactive and re-active public planning. The World can play a stimulating role in the development and implementation of policies in this promising field of integrated landuse/transportation planning. Such a role calls for the incorporation of effective and feasible planning concepts and institutional innovations, and further harmonisation in the field of planning regulations and procedures. 


\subsection{Policies for a Better Integration of Land-Use and Transport Planning}

As far as policy-related potentials are concerned, policies to better integrate land use and transport to reduce the need for travel and to make the remaining traffic sustainable were identified. The different policies were assigned to the following policy types: investment and services, planning, regulation, pricing, and information and informal policies.

When people walked to work, congestion was an issue, but it was a much smaller issue than car-created congestion. Cars take up so much more road space than consumers-both directly and indirectly through the distance needed between cars - that inevitably the introduction of cars created a massive increase in the problem of congestion.

The congestion problem is one of the most classic examples of a market failure, or externality in economics. The basic problem is that the time cost of commuting per commuter is increasing with the number of commuters. When any individual decides to drive to work, that individual takes into account the time cost of commuting to himself. However, this individual does not internalise the time cost that his commuting imposes on others. Put formally, the total time cost of commuting equals the number of drivers multiplied by time per driver, which is itself a function of the number of drivers. The private time cost faced by each driver equals just the time per driver. However, the social cost imposed by each driver equals the private cost (or time per driver) times the number of drivers times the change in time created by an extra driver. This second component is the externality, and it can be quite large. While the change in average commuting time created by a single extra driver is itself quite small, this change in average commute times must be multiplied by the overall number of drivers, which is an extremely large number. The product of these two numbers can be quite large; indeed the externality can larger than the private cost paid by drivers. The classic economic response to this type of externality is a tax on drivers equal to the externality, i.e. the number of current drivers times the marginal cost of extra time created by a new driver. In practice, this value may be difficult to estimate, and the size of tolls is frequently limited more by political considerations than by economics.

Nevertheless, the goal suggested by economics is to get people to internalise the social costs of their actions through some pricing mechanism. Once this goal is clear, then it is obvious that general taxes on driving will be extremely inefficient means of achieving this end. For example, gasoline taxes are often vaunted as one approach to congestion. But these taxes are too broad brush and often have unforeseen consequences. There is no reason for a traffic tax on cars driving on empty country roads. There is no reason to charge drivers for using city streets at 2 a.m. when there are no other cars on the road. Ideally, road taxes will be targeted so that people only pay when their driving increases congestion. The principle of targeting is important because it encourages substitution out of high congestion times and places into low congestion times and places. If all driving is taxed equally, as it is by a gas tax, then the tax does not encourage people to commute at off-peak hours rather than peak hours. However, much of the gains from commuting taxes will come from this type of intertemporal substitution. This it is particularly vital that taxes be tied to particular times of day, or better yet road usage.

\subsection{Implementing Road Taxes}

As a practical matter, there are really two different types of roads, which need to have congestion taxes. The simpler situation occurs when there are clear highways that can have tolls. These tolls can no be paid through a car-based transponder which will directly by tied 
to a credit card. Alternatively, individuals may pre-purchase credit on the transponder. In either case, the transponder works electronically with almost no need for the driver to slow down. As a result road tolls can occur with little reduction in road velocity.

Road tolls should ideally change based on road usage. In principle, there could be a fixed toll schedule that rises during peak hours of driving. It is important for the changes over time not to be too discrete, so there doesn't develop a bulge of road use immediately before fees go up. An even more sophisticated approach is to have the fee directly tied to current road use. This fee would then be reported to consumers at the point that they are making their decision about using the road. In either case, the goal is to have the road tolls be closely tied to the actual road conditions.

On dense central city streets, a toll on each street will not be an efficient solution to the congestion problem. The costs of administering the system will overwhelm the benefits from pricing congestion. A feasible alternative is to use cordon pricing, such as the system pioneered by Singapore. In this system, drivers need to pay to use roads within a given geographic area. As such, on a monthly (or weekly or daily basis) drivers will need to purchase the right to use the roads. This can be administered through a fairly primitive sticker technology where individuals who have paid will have to display a visible sticker. In principle, this can be replaced by transponder technology, which alerts the police if drivers have not paid for their driving privileges. This system has the advantage of taxing drivers who want to drive in crowded central city areas. However, it has a few disadvantages. First, it will often create congestion right on the edge of the cordon. For example, since Singapore had a hefty fee associated with driving within the cordon (roughly one dollar daily) and no fee outside the cordon, congestion on the edge of the cordon get quite high.

A natural response to this problem is to have several geographic zones, which allow the driving fees to drop continuously instead of having one big drop. A continuous drop means that the gap between one zone and another will be smaller and want cause huge crowding on the edge of the cordoned area. Of course, it is crucial that there be real price differences, between the areas because the whole point is to induce drivers to substitute out of the high congestion area. A second disadvantage with cordon pricing is that it doesn't differentiate by time of day. Driving at 2 a.m. is just as expensive as driving at 9:30 a.m. In principle, this can be soled by allowing individuals to drive for free very late at night. An even more complicated system allows an array of permits that get cheaper as the hours associated with the permit become more restricted.

While economists have been unreservedly enthusiastic about pricing tolls for decades, congestion tolls have only been rarely implemented. This lack of implementation is associated with the general political unpopularity of these tolls. In part this unpopularity comes from the fact that tolls are yet another tax. Since implementing congestion tolls is something of an uphill battle, it seems important to figure out ways to make tolls more political palatable. Here are three suggestions. First, give people some initial free credits on the tolls. These credits can either be used to pay for the tolls or to reduce an individual's taxes. This basically just gives the cash from the tolls back to consumers, but still gets each individual consumer to face the cost of driving since by driving during peak hours, they lose the opportunity to use the credits, which can be used to pay taxes. Second, tie toll revenue to a politically popular form of spending, perhaps new roads or schools. Tolls can be made less unpopular if it seen that the income is going on something sensible. Finally, use highway tolls primarily on new roads. People generally respond with more hostility if an existing 
right is modified (i.e. by charging a toll on a road that used to be free) than if a new right is given with qualifications (i.e. if a new road is built, but that road requires a toll). While their will still probably be protests about tolls on new roads, they will be much less severe than protests on existing roads.

As a final point on road tolls, it is worthwhile emphasising the winners and losers from these tolls. Many people will gain from these tolls through quicker commute times. Poorer drivers may lose a little if they cannot substitute into lower commute tax times of commuting. However, the truly poor will really benefit. As they use public transportation (buses) not cars, the road taxes that they pay will be much less (per capita) than drivers. These poorer commuters will get all of the benefits of faster commute times with a much lower commute tax per person. As a result, these commute taxes will generally be progressive and they will help the poorest commuters.

Given the political costs of tolls, it is worthwhile emphasising why other approaches to limiting congestion are so inefficient. First, the pure supply approach of building new roads is basically doomed to failure. New roads are surely necessary, but the basic market failure will not go away with new roads. Moreover, without time-based tolls drivers will inefficiently use any new roads at peak times instead of spreading their usage over the day. Second, quantity controls on driving inevitably involve large efficiency losses. A classic example of such quantity controls is license-based driving restrictions. According to these policies, certain cars must not be used on certain days.

There are certain obvious inefficiencies of this system. For example, it is clearly inefficient to have a sizeable amount of the capital stock of a city (i.e. its cars) lie idle $20 \%$ of the time. Moreover, these restrictions compel richer drivers to purchase extra cars so that they can use their cars every day. This does impose a cost on drivers, but this cost is pure social waste. Whereas a toll turns produces income that can be used for any other social purpose, spending on buying extra cars is just wasteful. These quantity restrictions also create less obvious social waste that can be avoided with tolls.

The beauty of road taxes is that they do not prevent people who really need to drive from using the roads. They just require that these people pay for the social costs of their actions. However, quantity controls require everyone to stop driving for some period of time. If those people really need to use the road during that time period, the law makes no allowance. The law doesn't allow the people who value the roads most to use them, instead it inefficiently blocks everyone. This is why economists almost universally prefer taxes to command and control restrictions.

\subsection{Public-Private Co-operation and Partnerships}

The creation of a public-private partnership offered a lot of advantages for financing the project as well as fostering operating processes. Planning stages were shorter than in an administrative way, flexibility in reacting on new developments was ensured. At the same time, it ensured the compliance with the ecological concepts.

\subsection{Local Public and Private Parties in Land Use and Transport Planning}

Vertical co-ordination does not leave much space for regional initiatives and is often seen as restrictive. Local governments ask for more and more flexibility and decentralisation. The local public and private parties should be prime actors, making a comprehensive regional land use and transportation plan without to much interference of national concepts, which 
are not adapted to their specific regional needs. The different parties should come to an agreement in a contract, which should contain measurable standards to achieve. The national government, which is one of the parties, could monitor the process using these agreed standards and adapt their financial support on the effectiveness of the local policy.

\subsection{Project Financial Responsibility should be Borne by all Partners}

Complex urban planning projects require a true political desire, which is defined in urban development documents and results in preserving land sites for the future even if it is a long term plan. They also need an appropriately set up structure to control all development work, through a public-private partnership. The financial risks of the project must be borne by all partners. In particular, banks, when present, must not limit themselves to being part of the structure simply to provide funds to operators and property developers who will be responsible for construction work.

\subsection{Possibilities for Development of Sustainable Transport and Land Use Structures}

It is important to identify measures in order to reach the development of sustainable transport and land use structures. These steps should not be isolated from each other. These measures can be divided in the field of spatial organisation and the field of transportation. To give an overview about measures in different spatial levels, case studies show projects, which were implemented in the national, regional, local, or district level.

Measures in the field of social integration, citizens communication and participation are useful to support these measures and are also taken into account. Spatial structures reducing distances between urban functions can be considered as an important precondition for decreasing traffic, especially traffic caused by motorised modes.

The measures can be subordinated under the following statement: a revision of spatial organisation or the development of spatial organisations in areas with future development that fit into traffic-reducing concepts. Vice versa, land use planning must recognise existing transport structures: for instance the development of a new area intending to promote less car dependency but with easy connection to a motorway may not be successful. The following measures could fit into an integrated concept: (a) Assign functions (housing, working, leisure, education, supply+services) on the urban/regional scale; (b) Development of mixed used structures; (c) De-central concentration; (d) Creation of dense, compact structures; (e) Protection of landscape and nature and reduction of land consumption by avoiding urban sprawl; (f) Redevelopment in existing structures; (g) Infill development on vacant land in existing structures; (h) Concentration of urban development around public transport stops; (i) Create concentrated development nodes which allow for public transport to be economically feasible; (j) Give attention to developing high quality public spaces to attract the public and create liveable cities; and (k) Measures of transport planning. Land use planning should also consider existing transport structures. The following are examples for measures in the field of transportation planning that promote sustainability: (a) Promotion of public transport (allowing for quantitative and qualitative improvements in order to make public transport competitive with car use); (b) Improvement of accessibility of public transport; (c) Promotion of non-motorised transport (by making quantitative and qualitative improvements); (d) Promotion of transportation intermodal; (e) Influencing car usage (reducing traffic, traffic calming, parking management); and (f) Networking regional economy and production. 
Referring to the sustainable triangle mentioned early, creating social equity is one important aim in urban sustainability. Social equity could be defined as giving all inhabitants of a city the opportunity to satisfy their demands and needs. Different social groups also have different demands on mobility. A consideration of these demands in an integrated transport and land use system could promote the accessibility of different social groups to cities facilities. People without cars should be given the opportunity to reach important locations by public transport, bike or walking. Conversely, the reduction of social inequity and social integration could influence spatial structures as well as the capacity of public transport. Reduction of social segregation could be related to public participation. Involvement of different social groups in decision-making helps to ensure that land use patterns meet the needs of these social groups. If mixed use facilities meet the demands of social groups living in a district than car mobility can be reduced. Some measures in this term are: (a) Increasing accessibility to transport networks; (b) Mix of private and public investors in building new districts; (c) Increasing accessibility to social, cultural life and working / education; and (d) Implementation of mix use to offer low distances for people without an own car.

Public participation as well as public awareness in order to ensure the acceptance of the above mentioned integrated planning goals must be considered as an important part of integrated transport and land use projects. Public information and participation can reduce social barriers which could hinder the implementation of planning tools promoting sustainability. Creating awareness among citizens about the disadvantages of car usage could, for example, promote the usage of public transport and non-motorised modes. The measures in this aspect are: (a) Create awareness to the public about mobility related problems; (b) Create awareness to the public for another mobility behaviour; (c) Influencing private housing preferences by awareness campaigns to promote higher population density; (d) Citizens' participation in planning and redeveloping of structures; (e) Citizens' participation in planning and implementation of new districts to promote local identity; (f) Informing citizens about the advantages of integrated measures; and (g) Information should be made available and participation by stakeholders, decision-makers and politicians involved in the project should be promoted.

The following groups have been identified as those who are targeted by implementation of best practice in the field of integrated transport and land use planning, who can use best practice and how they can profit from its use: (a) Planners - best practice as an example of a successful integrated planning approach. The successful implementation of a previous project can serve as a motivation. Such practices can help planners to choose the right planning measures for their particular project; (b) Citizens - must be informed that their quality of life will improve if they use best practice (this is very important especially with car use restrictions since such restrictions are not popular). Many measures towards integration could help reduce an existing social imbalance in cities. Certain social groups rely on public transport, bicycles, or travelling by foot due to objective and subjective dependency. Such groups profit by integration. Land use patterns (mixed use, density), public transport infrastructure investment and the promotion of non-motorised transport can facilitate access to urban functions by such social groups; (c) Decision-Makers - planning instruments which have been successful in the past are more likely to be accepted by policy makers; and (d) Investors - projects are more likely to be supported by investors if proven instruments or elements of best practice are used to reduce doubt by investors. 


\section{Lessons Learned}

The construction of adequate public transport facilities is one of most problematic issues when implementing a housing policy. As large investments are necessarily required, it is safe to assume that considerable delays may be expected with negative pitfalls on the quality of service. These problems can be averted if (private) public transport companies were to be included at an earlier stage in the policy planning process.

Citizens' participation is pivotal for creating mixed-use areas. The shaping of traditional European cities leads to postulate that mixed-used areas are not the result of detailed planning - as they are more the outcome of spontaneous development. According to this assumption, self-organisation and citizens participation in developing mixed-used districts (not only in the planning and building stage) is one of the preconditions for creating a mixed-used area accepted by its inhabitants for a long time.

Shopping malls can compete with businesses located in well-integrated mixed-use city centres. Well-situated customers prefer shopping in malls, but also distant shoppers accept long travel distances, long travel time, as well as congestion in order to shop there. Campaigns informing that time is not gained when driving to non-integrated shopping centres in peak hours and public transport must be promoted to influence customers.

Location policies successfully regulate public and private investments and have strongly strengthened the vitality of the cities. Firstly, they can concentrate public investments in infrastructure and public transport within the urban areas. Secondly, they can start large urban renewal programs to upgrade the inner city areas around major transport node urban locations, and thirdly they help to attract private investments to the city. Especially the strong development of locations reachable both by public transport and car can induce a new economic impulse for the urban economy. To make a location policy successful, the implementation of other transport policies and land use policies are necessary. The location policy can only function well when included into a well-balanced policy package. Furthermore, the success of this policy depends on the availability of all the accessibility profiles. Refrain from creating new planning bodies.

While it is correct that the integration between land use and transportation planning is in its essence a regional task, it must be concluded that it is worthwhile using existing legislation as much as possible, before creating new institutional bodies to handle the planning. It is advisable to implement a procedure for creating a "zone of consistency between urban development and transportation" that should provide proper means of controlling the occupation of land as long as transportation infrastructures are not in place. This procedure imposes actual monitoring of the various urban development projects. Therefore, projecting a situation at a given time horizon is not enough, it is necessary to plan for the intermediate steps and control the mechanisms to be implemented in order to limit inconsistencies.

Lack of integration between transport and land-use can cause negative mobility effects such as increased share of motorised modes, as well as increased travel times and travel distances. A rigid and vertical planning hierarchy results in a series of strictly independent local plans organised in general, partial and special plans, action programs and detailed studies which effectively cause a disconnect and lack of co-ordination between authorities and citizens. Such extreme top-down articulation leads to a deadlock, which can only be overcome when a shift towards a more co-ordinated and participatory planning approach is decided. It is difficult for integrated transport to work in a semi-rural area due to poor 
public transport. Therefore, an alternative option to encourage sustainability is to encourage people to live in close proximity to their place of work.

The lack of building laws and regulations fosters growth of poorly integrated developments. Information is crucial during project development. In planning a light rail system, there is the need for detailed design and to keep the public informed during construction. It is crucial that great care is taken in ensuring that all parties know of construction work and the public kept up-to-date by media announcements. Light rail systems require specialist operational management. Concentrating too much on engineering, design and organisation and not considering the operation of the scheme can harm the project.

\section{Transports Modalities}

To evaluate the economic impacts of transports we can use some tools to estimate the effects of a transportation system intervention and then evaluate the screening of options. The commonly used tools are: Analysis of cost $x$ benefit; Analysis of cost $x$ effectiveness.

The automobile has a contradictory relation with the tertiary Sector. During decades the automobile industry in partnership with oil industries had dominated the economy. Eight of the ten bigger companies of the world.

The revolution of the computer science and the media if had inserted in this universe of being able, without the automobile industry lost its. Until the sixties it had the ideal of the motorised city. In the following years all the problems for this had been being eliminated: (a) Weakness of the railroad mass transport; Extinguishing of the trams of cities as Rio de Janeiro; (b) Bigger investments, each time, had been made in infrastructure for the individual transport: parking buildings and new facilities that have occupied the urban land; (c) Congestion; Deterioration of the collective transport; Subordination of the collective transport on the individual one. The cities sow its transport capacity be reduced.

With the urban growth and the concentration of the tertiary Sector in monocenters cities with structure, flows of bigger traffic each time if directed to the centres of the cities causing a jam of flows. From a certain moment the tertiary Sector observes diseconomy for price increasing of the workmanship and reduction of the demand due the inaccessibility generated for the congestion. We can see that more land occupation of automobiles, strangling the tertiary Sector, It's a cumulative and cyclical process that must be controlled.

The concept of "living without an own car" has encountered difficulties due to the overestimation of the demand for this style of life, and it offered the opponents arguments against the implementation of the new policies. Therefore, pilot projects must be based on a solid background in order to face off the barriers posed by detractors. At present the only method of enforcing car-free living is the prevention of residents' parking within the development, through the lack of parking spaces and through residents' good will.

In the decade of 60 and 70 urban decentralisation was not accepted for the tertiary Sector that prefers centrality. In the decade of 90 and 00 this tendency was reversibly because tax incentives for services, industries and others facilities that supply a degree of self-sufficiency of services experimented for some metropolitan zones such Barra da Tijuca, located in the west zone of Rio De Janeiro. The change of commercial building Esso Co. from city to Barra da Tijuca is an example. For many people cars are not a relevant means of getting to work. Instead, they use large public buses, subways and smaller private buses, or jitneys. 
The subsidisation of public transportation is often vaunted as an alternative means of fighting congestion. While public transportation is quite important, economists tells us that subsidising buses is much less efficient that taxes cars are a means of fighting congestion. However, while buses shouldn't be subsidised, and indeed in principle buses should also be taxed for the congestion that they create, they are an extremely important part of the urban transportation landscape. They provide a very efficient means of moving poorer people to and from work. In particular, smaller buses, or jitneys, provide an unusually efficient means of getting poorer people to their jobs. As such, they should be recognised as an extremely valuable part of the urban transportation system.

Regulatory barriers should not prevent these jitneys from operating. Except for the principle of taxing congestion, there is no reason why free entry shouldn't be allowed and encouraged in the bus system. If this is allowed to go forward, there is no reason to doubt that Brazil will continue to have a healthy private bus system that delivers people to jobs. While buses are a efficient means of moving, subways are generally expensive in construction and operation. They are generally sold to the taxpayers with a variety of gimmicks, such as vastly over inflated rider ship projections. Serious economic estimates of the costs of subways tell us that these subways, for any level of rider ship are much less cost effective than buses.

A successful scheme is to have buses on dedicated bus lanes. Buses on these lanes can move as quickly as trains, but there is much more flexibility. Given the unpredictability of cities, it makes no sense to invest in expensive fixed infrastructure that can never cover its operating costs, let alone its construction costs.

Great investments on bikeways, and not just in the central city zones, seeking to form an attractive network, have increased the cycling share providing good cycling opportunities also for inhabitants living outside the downtown area. Such investments, suggest that cycling can be promoted as a mode of transport in both high and low density areas.

When promoting cycling, conflicts between pedestrians, car drivers and cyclists will inevitably arise but they can be solved with information campaigns, and by means of restrictions (dividing pedestrian and cycling areas, prohibition of cycling in pedestrian areas and vice versa). Interesting design and landscaping will encourage potential residents who are considering living in a car-free environment.

\section{Conclusions}

Land-use and transport policies are only successful with respect to criteria essential for sustainable urban transport (reduction of travel distances and travel time and reduction of share of car travel) if they make car travel less attractive (i.e. more expensive or slower)(Transland, 2000).

Land-use policies to increase urban density or mixed land use without accompanying measures to make car travel more expensive or slower have only little effect, as people will continue to make long trips to maximise opportunities within their travel-cost and travel time budgets. However, these policies are important in the long run as they provide the preconditions for a less car-dependent urban way of life in the future.

Transport policies making car travel less attractive (more expensive or slower) are very effective in achieving the goals of reduction of travel distance and share of car travel. However, they depend on a spatial organisation that is not too dispersed. In addition, 
highly diversified labour markets and different work places of workers in multiple-worker households set limits to an optimum co-ordination of work places and residences.

Large spatially not integrated retail and leisure facilities increase the distance travelled by car and the share of car travel. Land-use policies to prevent the development of such facilities are more effective than land-use policies aimed at promoting high-density, mixeduse development. Fears that land-use and transport policies designed to constrain the use of cars in city centres are detrimental to the economic viability of city centres have in no case been confirmed by reality (except in cases where at the same time massive retail developments at peripheral Greenfield locations have been approved).

Transport policies to improve the attractiveness of public transport have in general not led to a major reduction of car travel, attracted only little development at public transport stations, but contributed to further sub urbanisation of population. In summary, if land-use and transport policies are compared, transport policies are by far more direct and efficient in achieving sustainable urban transport. However, accompanying and supporting land-use policies are essential for in the long run creating less car-dependent cities. The leading objective of land-use and transport planning is to reduce the need for travel and to promote sustainable transport. Different policies were assigned to policy types: investment and services, planning, regulation, pricing and information, and informal policies.

Due to their interdependent effects policies of land-use and transport need to be combined to reach the sustainable objectives. This mainly refers to the relationship of investment and services and planning on the one hand and regulation, pricing and to a certain extent information on the other hand. Most policies relating to planning and investment, while necessary, are not adequate by themselves to reduce the need for travel and to reach sustainable transport. Their successful implementation is only possible if additional pricing and regulatory policies create the necessary frameworks.

Planning and investment policies are nevertheless the most important means to reduce the need for travel because they influence land-use, traffic infrastructure and travel behaviour. However, they often must be coupled with pricing and regulatory policies, which not only support the planning and investment policies but also promote a change in the settlement behaviour, a reduction of land-consumption and support an efficient use of the transport network. It can be concluded that all policies are important and they can be used in combination to lead to successful implementation.

The realisation of the policies can be restricted or prevented by different types of barriers, including resource barriers, social/political, legal and institutional barriers, as well as side effects. These barriers determine the feasibility and transferability of policies. It can be concluded that all policy types, except information policies, face several barriers, with planning and investment mainly being restricted by institutional barriers and pricing and regulatory policies mainly facing social barriers. Information policies, which are limited in their effects on reducing the need to travel, hardly face any barriers. The future of cities is intrinsically bound up with transportation technologies.

Cars have changed urban form and will continue to change urban form. However, unless the congestion problem is solved, cities will not hobbled with the extremely costly problem of long commute times. The congestion problem is a classic externality problem where drivers don't take into account the cost of their driving on others. The best solution to this problem is a traffic toll that is targeted at specific roads during specific time periods. Less direct taxes will be much less efficient at reducing congestion. 
Quantity controls, such as license plate based restrictions on days of driving, are also quite inefficient. Public transportation will continue to play a role in urban transportation for the foreseeable future. However, all of the economic analyses of public transportation suggest that subways are extremely costly, inefficient means of solving the transportation problem. There is nothing that a subway can do that can't be done better by a dedicated bus line. As such, it is crucial that Brazil not wastes money only in an expensive subway extensions but rather improve the bus infrastructure and operation instead.

To avoid the stimulating automobile use, a good and relatively cheapest option is to turn some shared road spaces into preferential and/or exclusively bus lane. This practice will convert mix bus/auto modal to bus priority modal capacity and will turn less attractive the use of automobile, in accordance with Transland studies. This solution only will be effective if the lane will be in the same direction of jam flow, otherwise the use of automobile will be increased and the problem will be greater.

The level of service of bus modal in preferred or exclusive lanes must be better than before. Time will be reduced by the speed increase naturally. There must be interventions in the end of exclusive lanes and intermodal terminals in such a way to turn the solution integrated and equilibrated. To avoid the interference of right turns, the access of buses could be made by a left door, utilising the central spaces of streets. Bikeways integrating this buses terminal could be a good solution for short and meddle distances of commute and also complain with ambient aspects.

\section{References}

Ben-Akiva, M.E. \& Lerman, S. (1985). Discrete Choice Analysis: Theory and Application to Travel Demand, Cambridge, MA: MIT Press

Ben-Akiva, M.E. (1974). Structure of passenger travel demand models, Transportation Research Record 526, pp. 26-41

Ben-Akiva, M.E., Bowman, J.L. \& Gopinath, D. (1996). Travel demand model system for the information era, Transportation 23, pp. 241-266

Developing the citizen's network (1998). Why good local and regional passenger transport is important, and how the European Commission is helping to bring it about, COM (98) 431 final

ESTEEM Consortium (1998). ESTEEM, Final Report, Roma: ISIS

Green Book (2004). A Policy on Geometric Design of Highways and Streets, AASHTO, 5th Edition, ISBN Number: 1-56051-263-6

PDTU (2001). Plano Diretor de Transportes Urbanos, Governo do Estado Rio de Janeiro, Secretaria de Estado de Transportes, Companhia Estadual de Engenharia de Transportes e Logística, Central

Transland UR-98-RS-3055 (2000). Integration of Transport and Land Use Planning, Paulley, N. \& Pedler, A., Transportation Research Laboratory - TRL, London

Williams, K. (2005). Spatial Planning, Urban Form And Sustainable Transport (Urban Planning and Environment), Ashgate Publishing, ISBN-10: 0754642518 ISBN-13: 978-0754642510, United States 


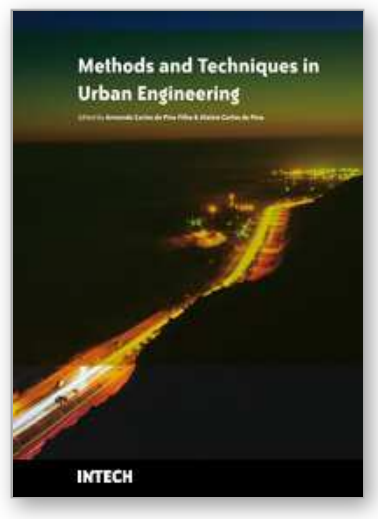

\author{
Methods and Techniques in Urban Engineering \\ Edited by Armando Carlos de Pina Filho and Aloisio Carlos de Pina
}

ISBN 978-953-307-096-4

Hard cover, 262 pages

Publisher InTech

Published online 01, May, 2010

Published in print edition May, 2010

A series of urban problems such as dwelling deficit, infrastructure problems, inefficient services, environmental pollution, etc. can be observed in many countries. Urban Engineering searches solutions for these problems using a conjoined system of planning, management and technology. A great deal of research is devoted to application of instruments, methodologies and tools for monitoring and acquisition of data, based on the factual experience and computational modeling. The objective of the book was to present works related to urban automation, geographic information systems (GIS), analysis, monitoring and management of urban noise, floods and transports, information technology applied to the cities, tools for urban simulation, social monitoring and control of urban policies, sustainability, etc., demonstrating methods and techniques applied in Urban Engineering. Considering all the interesting information presented, the book can offer some aid in creating new research, as well as incite the interest of people for this area of study, since Urban Engineering is fundamental for city development.

\title{
How to reference
}

In order to correctly reference this scholarly work, feel free to copy and paste the following:

Giovani Manso Avila (2010). A Contribution to Urban Transport System Analyses and Planning in Developing Countries, Methods and Techniques in Urban Engineering, Armando Carlos de Pina Filho and Aloisio Carlos de Pina (Ed.), ISBN: 978-953-307-096-4, InTech, Available from: http://www.intechopen.com/books/methodsand-techniques-in-urban-engineering/a-contribution-to-urban-transport-system-analyses-and-planning-indeveloping-countries

\section{INTECH}

open science | open minds

\section{InTech Europe}

University Campus STeP Ri

Slavka Krautzeka 83/A

51000 Rijeka, Croatia

Phone: +385 (51) 770447

Fax: +385 (51) 686166

www.intechopen.com

\section{InTech China}

Unit 405, Office Block, Hotel Equatorial Shanghai

No.65, Yan An Road (West), Shanghai, 200040, China 中国上海市延安西路65号上海国际贵都大饭店办公楼405单元

Phone: +86-21-62489820

Fax: +86-21-62489821 
(C) 2010 The Author(s). Licensee IntechOpen. This chapter is distributed under the terms of the Creative Commons Attribution-NonCommercialShareAlike-3.0 License, which permits use, distribution and reproduction for non-commercial purposes, provided the original is properly cited and derivative works building on this content are distributed under the same license. 